\title{
LA PRENSA AMARILLISTA Y LA PRENSA TRADICIONAL EN LA GUERRA HISPANO- ESTADOUNIDENSE (1898)
}

\author{
Santiago Mayochi* \\ Pontificia Universidad Católica Argentina \\ $\triangle$ santiagomayochi@gmail.com
}

Recibido: 23 de octubre de 2020

Aceptado: 26 de mayo de 2021

DOI: 10.46553/colec.32.2.2021.p13-53

Resumen: La Guerra Hispano-estadounidense fue muy apoyada por el periodismo estadounidense que, en ese entonces se encontraba en pleno crecimiento gracias a las nuevas tecnologías. No solo había aumentado la cantidad de diarios y la circulación de los mismos, sino que también había surgido una nueva forma de hacer periodismo, el amarillismo. Esta guerra sería el escenario donde el máximo representante de este periodismo amarillista, William Randolph Hearst, y el máximo representante del periodismo tradicional, Adolph Ochs, expondrían sus métodos periodísticos, su objetividad, su solvencia económica y su capacidad para obtener noticias y hacerlas llegar al público. Ambos hombres, cada uno desde su diario, el New York Journal y el New York Times respectivamente, defenderían la expansión y el intervencionismo de su país, pero de formas muy distintas. Este trabajo pretende demostrar cómo cada diario se acomodó a esta lógica imperialista, cada uno desde su estilo.

Palabras clave: Guerra Hispano-estadounidense; periodismo amarillista; William Randolph Hearst; periodismo tradicional; Adolph Ochs; New York Journal; New York Times

\footnotetext{
* Profesor y Licenciado en Historia por la Universidad Católica Argentina. Se desempeña como profesor asistente en la misma universidad y como docente en diversos colegios secundarios.
} 


\begin{abstract}
The Spanish-American War was very supported by the American journalism which by then was growing thanks to the new technologies. Not only the amount of newspapers and its circulation had augmented, there was also a new way to do journalism, the yellow press. This war would be the scenario were the mayor exponent of the yellow press, William Randolph Hearst, and the mayor exponent of the traditional press, Adolph Ochs, would expose their methods, their objectivity, their economic solvency and their capability to obtain the news and deliver them to the public. Both men, each one from their own newspaper, the New York Journal and The New York Times, defended the expansion of their country, but in very different ways. This paper's objective is to demonstrate how each newspaper manage the imperial logic in their own way.
\end{abstract}

Keywords: Spanish-American War; Yellow Journalism; William Randolph Hearst; Traditional Press; Adolph Ochs; New York Journal; New York Times

\title{
I. Introducción
}

A fines del siglo XIX, el periodismo en Estados Unidos atravesó un importante proceso de modernización. La población del país creció, sobre todo en las grandes ciudades, y los nuevos inventos como el telégrafo, las imprentas y las máquinas de escribir aumentaron el flujo de noticias. Surgieron también nuevos periódicos que ya no dependían del financiamiento de un partido político, sino del dinero que sus ventas generaran. El periodismo se convirtió entonces en una empresa comercial y el objetivo dejó de ser el privilegio político para ser, en cambio, el generar tantos lectores como fuera posible, abaratando los costos al máximo (Smythe 2003). Todo esto produjo la creación de nuevos diarios y un enorme aumento de la circulación con epicentro en la ciudad de Nueva York, la más poblada del país (Pomerantz 1958, 53).

Con más de veinte diarios en inglés y media docena en lenguas extranjeras, Nueva York era el lugar donde todos los periodistas del país querían trabajar. Uno de los principales periódicos de la ciudad era el New 
York Times fundado en 1851 y comprado en 1896 por Adolph Ochs ${ }^{1}$. Cuando Ochs lo compró, el diario estaba prácticamente en bancarrota y tenía una tirada de apenas 9.000 ejemplares. Sin embargo, a partir de la nueva dirigencia, el Times se convirtió en el diario profesional por excelencia, alcanzando gran reconocimiento nacional e internacional. Por profesional nos referimos al tipo de prensa que explicaba los hechos de manera imparcial sin tergiversarlos. En la vereda opuesta, se posicionaba el New York Journal, fundado en 1895 por William Randolph Hearst ${ }^{2}$. Este diario, se convirtió rápidamente en uno de los máximos representantes del denominado periodismo amarillista (Bosch 2010), una política de activismo agresivo para traer a la luz incidentes inusuales y explotarlos para aumentar las ventas (Wilkerson 1967).

Uno de los temas más utilizado por Hearst para aumentar sus ventas fue la guerra que Cuba estaba librando para independizarse de España. Para estos años, Cuba era, junto con Puerto Rico, la última posesión americana del Imperio Español. Desde el comienzo, los estadounidenses siguieron muy de cerca esta guerra, ya que tenía grandes capitales invertidos en la industria del azúcar cubano. Para la década de 1890, Cuba comerciaba más con Estados Unidos que con España. Además 800 ciudadanos estadounidenses estaban viviendo en Cuba, peligrando sus vidas y sus propiedades en ese contexto bélico. En Estados Unidos vivían muchos exiliados cubanos, quienes insistían constantemente en la necesidad de que Estados Unidos interviniese en el conflicto. Las noticias que llegaban al país sobre la situación de los cubanos conmovían a la población, ya que la guerra era sangrienta y devastadora (Bachrach 1991).

\footnotetext{
${ }^{1}$ Adolph Ochs (1858-1935) nació en Ohio y era hijo de inmigrantes judíos de Bavaria. Trabajó en periodismo desde los 19 años. En 1896, a los 38 años, un reportero del New York Times le avisó que el diario podría ser comprado a un precio reducido debido a sus recientes pérdidas financieras (Davis 1921).

2 William Randolph Hearst (1863-1941) fue criado en California, en una familia acomodada dueña de una mina. En septiembre de 1895 adquirió el periódico The Morning Journal que a partir de entonces pasó a llamarse New York Journal, cuyo primer número salió el 7 de noviembre de 1895. En unos pocos meses Hearst comenzó una guerra de ventas con el hasta entonces indiscutido rey de la prensa Joseph Pulitzer, dueño del New York World. (Whyte 2009).
} 
Tanto el Journal como el Times dieron su apoyo a Cuba en este conflicto, pero de formas muy diferentes, como ya veremos. El gobierno de Estados Unidos se mantuvo apartado del conflicto hasta que el 15 de febrero de 1898, el acorazado Maine hizo explosión cerca de las costas de La Habana. De los 354 hombres a bordo, 266 perdieron la vida. El New York Journal se apresuró a señalar al gobierno de España como el responsable, mientras que el New York Times llamaba a actuar con cautela y moderación ante lo que consideraban que podía haber sido un accidente. No obstante, con el correr de los días el New York Times viraría hacia una posición favorable a la intervención en Cuba, considerándola como algo necesario, aunque indeseado (Gleijeses 2003, 708).

Las relaciones entre Estados Unidos y España continuarían tensándose hasta que, el 25 de abril, el Congreso estadounidense declaró la guerra, justificando la intervención en este conflicto por motivos humanitarios, por el desgobierno español, y por la protección de los ciudadanos e intereses norteamericanos (Bosch 2010). Ambos diarios, cada uno con su estilo, seguirían comentando los avatares de esta guerra que terminaría con la rendición del ejército español, el 12 de agosto de ese mismo año. Los intereses que representaba la isla hicieron que esos periódicos, modélicos cada uno en su estilo, confluyeran en una defensa común de los intereses norteamericanos en el Caribe. Pero esos intereses eran algo distinto para cada uno de estos diarios. La investigación busca demostrar las nutridas interacciones que existieron entre la política expansionista del gobierno federal de los Estados Unidos, y las retóricas y dinámicas periodísticas de los diarios neoyorkinos.

Para este trabajo nos apoyamos en ciertas conceptualizaciones e ideas sobre el "interés nacional" de Fareed Zakaria trabajadas en su libro De la riqueza al poder: los orígenes del liderazgo mundial de Estados Unidos (2000). Zakaria advierte que el concepto de interés nacional es difícil de definir, ya que el principal interés de una nación es la búsqueda de la seguridad, pero las grandes potencias pueden darse el lujo de definir sus intereses en términos que en ocasiones exceden en mucho sus requerimientos mínimos de seguridad (Zakaria 2000, 39). En este sentido, si bien el pueblo de los Estados Unidos no enfrentaba un peligro inminente, los diarios que aquí analizamos vieron el enfrentamiento con España como 
una amenaza a la seguridad y orientaron sus esfuerzos en crear la imagen de un país "amenazado".

Además, para distinguir las diversas prácticas implementadas por los diarios que analizamos aquí nos es útil referirnos a la teoría del choque de paradigmas de W. Joseph Campbell (2013). Según él, para 1897 ya estaban delineadas en la prensa norteamericana, con epicentro en Nueva York, dos líneas editoriales. El periodismo amarillista del New York Journal de Hearst, o periodismo activo como él lo definió; y el periodismo objetivo y distanciado del New York Times de Ochs (Campbell 2013).

Aquí abordaremos las prácticas de ambos periódicos en el trascurso de la guerra, desde el 16 de febrero de 1898, día en que la prensa dio a conocer la explosión del Maine (ocurrida la noche del día anterior), y el 13 de agosto del mismo año, día en que la prensa anunció la rendición de las fuerzas españolas (lo cual había sucedido un día antes).

El New York Journal ha sido analizado por la historiografía norteamericana de diversas maneras. En forma individual, en comparación a otros diarios amarillistas (especialmente el World), y dentro de la prensa en general; pero ningún trabajo lo ha tomado como un caso específico de comparación a la prensa tradicional. Por eso este trabajo se propone comparar al máximo representante del amarillismo (el New York Journal) con el máximo representante del periodismo tradicional (el New York Times) para así diferenciar claramente sus métodos periodísticos, su retórica respecto al interés nacional y su cobertura ante el reportaje del mismo suceso: la guerra hispano-estadounidense.

Al hacerlo, intentaremos demostrar puntos de interacción entre la política expansionista propiciada por el gobierno federal, el clima de opinión de las grandes ciudades estadounidenses -especialmente el caso de Nueva Yorky los modos en los que la prensa relató -y en algún caso, incentivó- dichos episodios. 


\section{La prensa amarillista y la prensa tradicional}

\section{II.1. El éxito de Hearst}

La práctica del amarillismo es tan antigua como el periodismo, pero es en esta época donde se adopta el término, en el contexto de la guerra de ventas entre William Hearst y Joseph Pulitzer ${ }^{3}$. El New York World, el diario de mayor tirada en la Nueva York de aquel entonces, poseía una tira cómica llamada The Yellow Kid ("el niño amarillo"). El protagonista de esta tira era un niño irreverente de los barrios bajos de la ciudad que usaba una remera amarilla grande que le llegaba hasta los pies con frases divertidas en ella. Las tiras cómicas siempre mostraban a este personaje actuando como un inadaptado y metiéndose en problemas a causa de ello. Cuando empezó su competencia con Pulitzer, lo primero que hizo Hearst fue proveerse del mejor equipo que el dinero pudiese pagar. Para eso les ofreció salarios muchísimo más altos a los empleados del World, para que abandonasen el diario y en su lugar trabajasen para el Journal. En octubre de 1896, utilizando esta táctica, Hearst consiguió al caricaturista del World. Pulitzer, entonces, contrató a otro dibujante para que siguiera haciendo la tira cómica en su diario. The Yellow Kid se convirtió así en un personaje de ambos diarios. En enero del año siguiente, un periodista llamado Ervin Wardman del New York Press, usó el término yellow press ("prensa amarilla") para referirse a ambos diarios por primera vez. Aparentemente, la tinta amarilla de la caricatura solía correrse por la mala calidad de las imprentas, manchando todo el periódico de color amarillo. Para 1898 el término ya era usado en diarios de todo el país (Campbell 2001, 25-26).

En lugar de combatir esto, a mediados de mayo de 1898, el Journal abrazó el término amarillismo identificándose con íconos patrióticos:

\footnotetext{
3 Joseph Pulitzer (1847-1911) era un inmigrante húngaro quien arribó a los Estados Unidos en 1864 para luchar en la Guerra de Secesión. Luego de eso se unió al Partido Republicano y comenzó a trabajar en la prensa, desarrollando su capacidad de llevarle las exclusivas al hombre corriente. Para 1883 ya había amasado una fortuna y compró el New York World. Bajo su dirección, este diario pasó de 15.000 a 600.000 ejemplares, convirtiéndolo en el primer periódico del país de larga difusión. En estas condiciones se encontraba cuando Hearst y el New York Journal entraron en escena (Monclús 1998).
} 
Cada innovador del mundo ha sido conocido como amarillo por aquella masa de hombres que impiden el progreso de la civilización en cada país, en cada época. César era amarillo para los plutócratas del Senado romano. Napoleón era amarillo para los estrategas tradicionales a quienes venció desafiando sus reglas. Washington era amarillo para los tories, y también lo eran Jefferson, Franklin, Paine y todos los grandes hombres que crearon esta república. Los Estados Unidos están haciendo algo muy amarillo al involucrarse en esta guerra [la guerra de Cuba] para ayudar al prójimo en vez de llenarse sus propios bolsillos. El sol en el cielo es amarillo. El sol que es para esta tierra lo que el Journal es para el periodismo estadounidense. (Campbell 2001, 38-39)

La prensa tradicional se mantenía alejada de las masas, explicando la realidad político-económica del país con un lenguaje demasiado difícil de entender para el pueblo escasamente letrado. La prensa amarillista, en cambio, se acercó a las masas utilizando un lenguaje diferente, más cercano, y que hizo partícipe a toda la sociedad de los cambios acontecidos en el siglo XIX. Es así como comienzan a aparecer los titulares, las entradillas y la estructura de pirámide invertida. También aparecen los niños que venden los ejemplares gritando los titulares más importantes del día para atraer al público (Saad 2011, 2-3). Este método sería adoptado también, casi al instante, por la prensa tradicional.

Pero el éxito de Hearst no se explica solo por su nacionalismo o su lenguaje sencillo. También jugó un papel importante su bajo precio de venta. El 4 de enero de 1898, el diario bajó su precio a un centavo, mientras que los diarios de la prensa tradicional costaban tres centavos. Entre enero y octubre, el Journal vendió más de 110.000 diarios por día, mientras que el New York Times vendió solo 25.700 por día (Glazier 2004, 9).

El New York Journal, además, contaba con más publicidad que los diarios tradicionales. En esta época, donde no existía la competencia de la radio, la televisión o el Internet, los diarios usaban varias de sus páginas para promocionar distintos productos (Campbell 2006, 34). De las seis a ocho páginas que poseía el Journal, tres eran anuncios publicitarios. Mientras que los diarios tradicionales tenían entre cuatro y seis páginas con una sola página de anuncios. Entre 1890 y 1900, la prensa amarillista atrajo 350.000 .000 de anuncios por año a cinco centavos cada uno, lo que 
representó el 55\% de sus ingresos. Mientras tanto, la prensa tradicional, de 1890 a 1900, publicó 115.000 .000 de anuncios al año a seis centavos cada uno, lo que representó el 45\% de sus ingresos (Glazier 2004, 10).

Otra diferencia que tuvo su impacto en las ventas fueron las fotos e ilustraciones. Los diarios amarillistas como el Journal, apegándose al dicho "una imagen vale más que mil palabras", introdujeron fotos en los diarios, mientras que los periódicos tradicionales como el Times no. Pero como las fotografias eran en blanco y negro y muchas veces eran borrosas y poco claras, estos diarios también utilizaron ilustraciones. Las fotografías e ilustraciones, combinadas con las nuevas técnicas de impresión a color, volvieron a los diarios más agradables a la vista, más fáciles de leer y, por supuesto, más impresionantes; se convirtieron en un elemento clave a la hora de captar lectores de escasa educación y recién llegados al país (Pomerantz 1958, 60-61).

El New York Journal gastaba más dinero que cualquier otro diario en la cobertura de las noticias. Hearst invertía grandes sumas de dinero para conseguir las últimas noticias y presentarlas de la forma más atractiva posible. Gracias a su fortuna familiar y al dinero que generaba el propio Journal, Hearst podía conseguir más fuentes de información, pagar más corresponsales y, en el caso de la guerra, enviar más embarcaciones a Cuba (Glazier 2004, 10-15). Hearst procuraba que sus reporteros estuviesen siempre donde sucedía o podía suceder algo importante. Cuando nada importante ocurría, la solución era recurrir a la provocación del suceso o suplir con la fantasía de sus redactores lo que la realidad no proporcionaba.

Entre los temas que trataban los diarios amarillistas destacaban los artículos seudocientíficos, las noticias sobre crímenes, divorcios y escándalos de los famosos y las actividades de los miembros de las casas reales europeas. En 1896, el diario de Hearst dedicó gran espacio a cubrir las elecciones presidenciales. El programa del partido republicano estaba a favor de la independencia cubana, pero su candidato, William McKinley, no se comprometió con ella. Por lo tanto, Hearst apoyó la candidatura de William Jennings Bryan del Partido Demócrata. Sin embargo, el triunfo fue para el primero.

Pero ninguno de estos temas estuvo tan presente en el New York Journal durante sus primeros años como la guerra de Cuba. Hearst comenzó a hacer campaña para la guerra tan pronto como su diario comenzó a publicar. 
Criticaba a las autoridades españolas por sus acciones y a las estadounidenses por su inacción. Invirtió gran cantidad de tiempo y de dinero en esta guerra que finalmente terminó por darle a su diario más de un millón de lectores diarios (Bosch 2010, 292).

\section{II.2. Ochs, el Times y la prensa tradicional}

Desde el punto de vista de la prensa tradicional, el estilo de diarios como el New York Journal y el New York World era deplorable. Era poco profesional, poco serio e indecente. Sus publicaciones solo eran rumores sin corroborar y una burla al buen nombre del periodismo tradicional. Pero lo peor de todo era que estos diarios tenían éxito. Adolph Ochs estaba dispuesto a demostrar que un diario tradicional y conservador podía ser tan exitoso y rentable como los nuevos diarios amarillistas, pero sin ser inmoral.

Este ideal se resumió en el nuevo slogan del diario, "All the News That's Fit to Print" ("Todas las Noticias Aptas para Imprimir"), publicado por primera vez el 26 de octubre de 1896 (una semana después de que Ochs tomó la dirección), y que sigue siendo publicado hoy en día en todos los ejemplares del diario (Davis 1921, 197-198). Con esto Ochs quiso dejar en claro que su diario no se dedicaría a publicar trivialidades ni rumores sensacionalistas, sino solo aquellas historias que fueran verdaderamente importantes y que tuviesen fuentes corroborarles. El Times sería imparcial y digno de confianza.

Ochs no tenía la fortuna de Hearst, pero tenía una más que amplia experiencia en periodismo y prensa, donde había trabajado toda su vida. Con una tirada que recientemente había bajado a los 9000 ejemplares por día y un serio déficit, lo único que el Times tenía para ofrecerle era su buen nombre (Obituario de Ochs 1935, 19). Pero para alguien como Ochs eso era suficiente.

A diferencia del Journal que dedicaba gran parte de sus ejemplares a la publicidad, ciertos anuncios fueron censurados y excluidos del Times. La razón era que muchas de estas publicidades eran sospechosas de fraude o que provenían de algún partido político. Ochs solo permitía anuncios honestos y apartidarios en su diario (Obituario de Ochs 1935, 26-27). Esto podría costarle dinero, o al menos la oportunidad de ganar más, pero sin duda le daba al periódico la imagen que él quería, un periódico honesto e 
imparcial, lo cual, en la Nueva York de fines del siglo XIX, era muy significativo.

Pronto los esfuerzos de Ochs comenzaron a rendir frutos. Durante su primer año la circulación se duplicó y el déficit se redujo un $80 \%$. Los demás diarios pronto reconocieron la recuperación del Times y en 1897 fue admitido en la Associated Press ${ }^{4}$, ganando acceso a las noticias de esta agencia (Obituario de Ochs 1935, 29).

Para seguir recuperándose Ochs tomó la decisión de bajar el precio del diario de tres centavos a solo uno, como los demás diarios de la ciudad. El nuevo dueño del Times creía que la gente leía diarios amarillistas porque estos eran más baratos, pero leerían otra clase de diario si este costara un precio que pudieran pagar. A pesar de lo que todos creían esta decisión fue un éxito. Para 1898 la circulación ya había superado los 25.000 ejemplares.

Respecto a la guerra en Cuba, el Times apoyó la independencia cubana como la única forma de que la paz y la estabilidad volviesen a la isla. Estados Unidos debía intervenir, pero no militarmente sino a través de la mediación diplomática. El Times consideraba la anexión innecesaria. Una Cuba independiente y socia de Estados Unidos era suficiente (Cortada 1974).

Este diario no deseaba la guerra con España y criticaba fuertemente a los diarios amarillistas por incitarla. Los acusaba de poco profesionales, de brindar falsos testimonios y de incitar a la opinión pública. Eran comunes los artículos donde pedían a sus lectores no dejarse llevar por el belicismo de estos diarios, ya que nada bueno podía provenir de una intervención armada. Sin embargo, la explosión del Maine terminaría por radicalizar su postura, volviéndolo favorable a la guerra; y para cuando esto ocurrió el New York Times ya había dejado de ser un diario agonizante para convertirse en un diario redituable económicamente, honesto, confiable y capaz de obtener las noticias de manera rápida, imprimirlas y hacérselas llegar al lector en poco tiempo. Todavía le quedaba un largo camino por recorrer, pero sus bases eran firmes.

${ }^{4}$ Agencia de noticias de varios diarios de Nueva York que compartían su información. 


\section{La guerra en Cuba}

\section{III.1. El interés de Estados Unidos por Cuba y su guerra}

Desde los primeros años del siglo XIX, los Estados Unidos consideraban que la isla de Cuba era una prolongación natural de su territorio, y que cuando esta se independizara de España, pasaría a formar parte de la Unión. Así como en 1819 el gobierno norteamericano le había comprado una parte de la Florida a España, a lo largo del siglo XIX, le hizo repetidas ofertas por Cuba. Sin embargo, todas fueron rechazadas (Zakaria 2000, 100).

La importancia estratégica de Cuba no solo era relevante para los Estados Unidos sino también para España. Hacia fines del siglo XIX, gracias a la especialización del procedimiento, se instaló en la isla el monocultivo de la caña de azúcar y se aumentó su productividad. Además, se convirtió en una cuestión de orgullo nacional probar que España podía retener Cuba a pesar de la pérdida de sus demás colonias en América. Para asegurarse el control de la isla, España envió tropas para que mantuvieran todo bajo un estricto control. Estas tropas eran brutales con los campesinos cubanos. Y a todo esto se sumaba una restrictiva política económica que gravaba con altos impuestos los productos de la isla. Por lo tanto, no es sorpresa que Cuba se alzara en una rebelión contra de España en 1868 en la llamada Guerra de los Diez Años (1868-1878) (Bachrach 1991, 10-15). Esta guerra terminó con algunas concesiones políticas y económicas, pero muy pequeñas y que no llegaron a cambiar la realidad de la isla. La más destacable fue un acuerdo comercial con Estados Unidos.

En febrero de 1895 estalló entonces otra revolución. La intención del presidente estadounidense Grover Cleveland era mantener el orden y la estabilidad para proteger las inversiones que los empresarios estadounidenses habían hecho en Cuba. Para tal fin, Cleveland decidió apoyar a España contra los rebeldes, pues se pensaba que esa era la manera más fácil de reestablecer el orden. Pero pronto se dio cuenta de que España había perdido el control de la situación, y que el caos resultante ponía en peligro los intereses norteamericanos, "que no eran, en modo alguno, de naturaleza completamente sentimental o filantrópica" (Zakaria 2000, 213 214). La manera de recuperar el control de la isla sería entonces el apoyo diplomático a la causa cubana. 
Ante la inferioridad numérica y material, los cubanos recurrieron a la guerrilla, evitando los enfrentamientos directos con el ejército español. Sus tácticas consistían en emboscadas rápidas en puntos estratégicos vulnerables como vías férreas, líneas telegráficas y plantaciones de azúcar. Ellos conocían bien el terreno, podían moverse sin ser detectados, vivir de la tierra, encontrar refugios, averiguar la ubicación de los españoles y escaparse sin dejar rastros (Smith 1994, 10-15).

Con el objetivo de terminar con esta guerra de guerrillas, en enero de 1896, el General Valeriano Weyler asumió el mando del ejército español e inició la política de concentrar civiles en pequeñas áreas fortificadas vigiladas por sus soldados para impedir que siguieran ayudando a los rebeldes. A partir de entonces, los campesinos fueron desalojados de sus granjas, y llevados a campos de concentración donde la mitad murió producto del hambre y las enfermedades. No solo cubanos sino también ciudadanos estadounidenses fueron llevados a estos campos.

Los líderes rebeldes esperaban que el público estadounidense apoyara su causa. Pensaban que con la ayuda de Estados Unidos podrían finalmente echar a España de la isla. Por esta razón enviaban emisarios para reportarle a los diarios estadounidenses sobre las crueldades cometidas por los soldados españoles. Es importante remarcar que tanto los españoles como los cubanos cometieron atrocidades durante la guerra. Sin embargo, a Estados Unidos solo llegaban las noticias del lado cubano porque las autoridades españolas no permitían a los reporteros acercarse al campo de batalla. Así que las únicas noticias que llegaban a los diarios norteamericanos eran sobre la opresión y barbarie de los españoles y del patriotismo y heró́smo de los cubanos. De esta manera, al pueblo norteamericano le llegó un relato sobre el movimiento independentista cubano muy victimizado, y cuya guerra de independencia le recordaba a la suya (Bachrach 1991, 18-19).

Para comienzos de 1898, los soldados españoles estaban mal alimentados, enfermos y faltos de sueño. Mientras más duraba la guerra, más costosa era la misma para España en vidas, dinero y moral; además del creciente riesgo de una intervención norteamericana (Smith 1994, 21-23). El secretario de estado de McKinley había dejado bien en claro que su país tenía intereses vitales en Cuba y sus aguas circundantes, y que no 
permanecería ocioso si España era incapaz de reestablecer la paz (Zakaria 2000, 218).

\section{III.2. La explosión del Maine}

El 24 de enero de 1898, luego de una rebelión de oficiales españoles en la Habana, el presidente McKinley había ordenado al acorazado Maine navegar a Cuba para poner a salvo las vidas de los estadounidenses que residían en la isla (Bachrach 1991, 23-24). Como ya dijimos antes, cientos de estadounidenses estaban viviendo en Cuba, además Estados Unidos tenía grandes capitales invertidos en la industria del azúcar cubano. Por lo tanto, el envío del Maine puede ser interpretado como un mensaje de los Estados Unidos a España de que sus intereses no podían seguir siendo ignorados.

El acorazado llegó a las costas de la Habana sin ningún problema y fue cordialmente recibido por las autoridades españolas, a pesar de que estas habían informado a los diplomáticos estadounidenses que consideraban la visita del acorazado como un acto poco amistoso. Exactamente a las 9:40 p.m. del 15 de febrero, una gran explosión tuvo lugar en el Maine. El barco se hundió rápidamente en las costas de la Habana y dos tercios de la tripulación perdieron la vida (Bachrach 1991, 25-26).

Lo primero que había que determinar era si la explosión había sido un ataque o simplemente un accidente. Para esto, estadounidenses y españoles, al no ponerse de acuerdo en una investigación conjunta, realizaron investigaciones por separado $\mathrm{y}$, como era de esperarse, las conclusiones a las que llegaron fueron muy diferentes. La investigación, realizada por reconocidos oficiales y expertos militares estadounidenses, concluyó que la explosión había sido provocada por una mina colocada en la zona inferior del acorazado. En tanto que la investigación española determinó que el Maine había sido diseñado con una carbonera demasiado cerca de las municiones. El carbón habría prendido espontáneamente produciendo la detonación de estas municiones. El Maine usaba carbón bituminoso como combustible, el cual podía explotar si no era apropiadamente ventilado, y las bodegas del Maine no lo estaban. Los españoles negaban así la colocación de mina alguna y se eximían de la responsabilidad de este incidente (Wilkerson 1967). 
Al día de hoy sigue sin saberse con certeza cuál fue la razón de la explosión.

\section{A la guerra.}

IV.1. El Journal: la obra de un enemigo

Más allá de las incertidumbres que envolvían la cuestión del Maine, el New York Journal, al día siguiente de la explosión, no dudó en acusar a España. En el titular podemos leer: "CRISIS ACTUAL, gabinete en sesión; crece la creencia de la TRAICIÓN ESPAÑOLA" (New York Journal, 16 de febrero de 1898). El uso de mayúsculas y minúsculas no es casual. Cuando el lector veía la portada, instintivamente leía la letra mayúscula. Mientras que leyendo el titular completo se puede advertir que la traición española era solo una posibilidad, al leer solo la mayúscula el lector podía llegar a pensar que se trataba de una certeza. 


\section{Imagen 1. New York Journal, 16 de febrero de 1898}

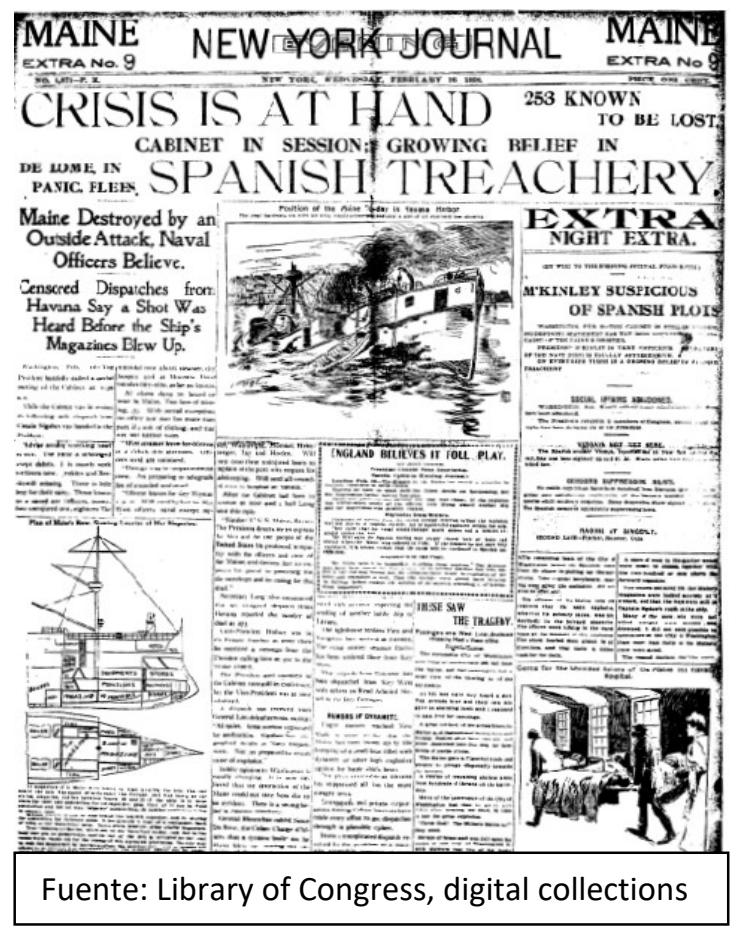

Los titulares "Oficiales creen que la explosión del Maine fue causada por un ataque naval externo" o "McKinley sospecha del complot español", eran solo creencias que no aportaban conclusiones objetivas. Además, el Journal señaló que se había escuchado un disparo previo a la explosión del Maine, pero atribuía esta información a fuentes secretas de La Habana, por lo que la fiabilidad de esta afirmación volvía a quedar en entredicho (New York Journal, 16 de febrero de 1898).

Un día después, el titular principal del diario de Hearst apuntaba a un enemigo de Estados Unidos como culpable de la explosión: "LA DESTRUCCIÓN DEL BARCO DE GUERRA MAINE FUE OBRA DEL ENEMIGO" (New York Journal, 17 de febrero de 1898). No se mencionaba a España en este titular, tan solo se discutía la idea de "enemigo", pero luego de ver la portada del día anterior era evidente a quién se refería. El Journal, en esta portada, señalaba que Theodore Roosevelt se mostraba "convencido 
de que la explosión no había sido un accidente". Roosevelt era un hombre con una postura fuertemente expansionista, así que no resultaba extraño pensar que esto fuera cierto, aunque la investigación oficial duró semanas y estas afirmaciones eran meras conjeturas en aquel momento.

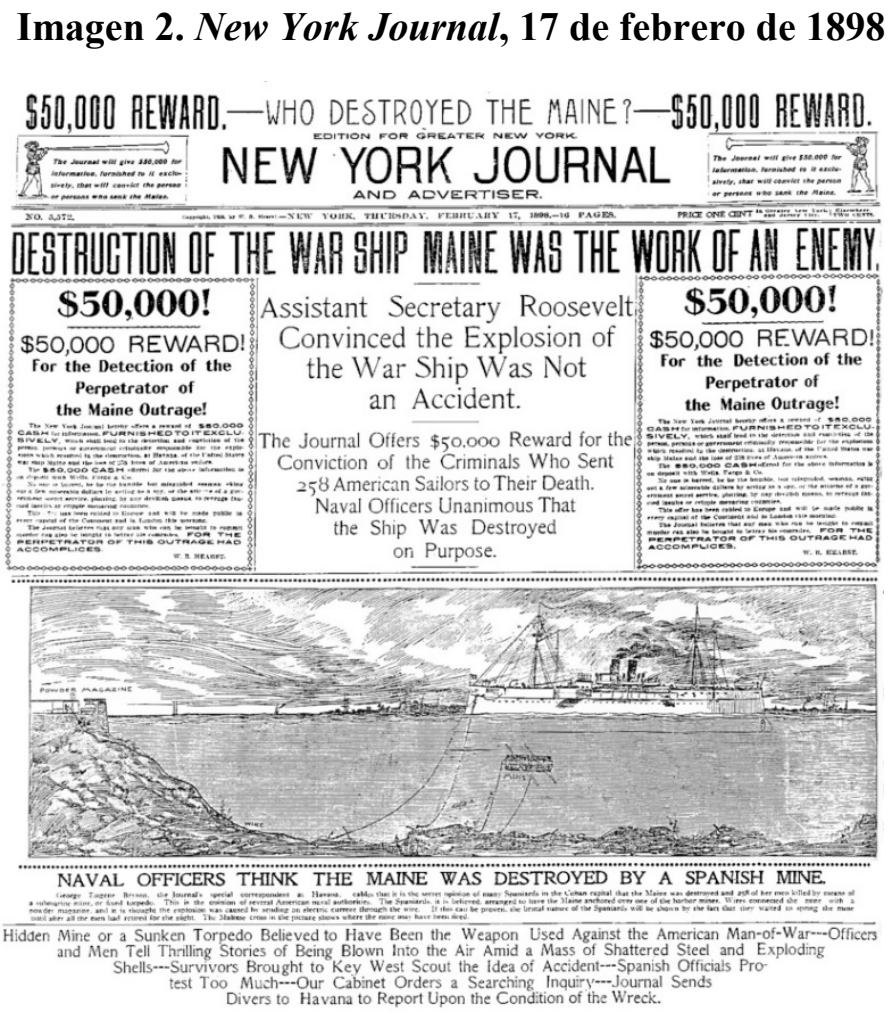

Fuente: Library of Congress, digital collections

Ya en la zona inferior de la portada es posible advertir la primera referencia a España: "Los oficiales de la marina creen que la explosión fue causada por una mina española". Y en la zona más baja, con letra pequeña, podemos leer "la sospecha de que el Maine fue destruido de forma deliberada aumenta cada hora. No hay nada que indique lo contrario" ( $\mathrm{New}$ York Journal, 17 de febrero de 1898). El Journal seguía dictando sentencia 
sin esperar a la investigación oficial. Además, en la única ilustración de la portada, observamos al acorazado conectado a varios cables y a una mina submarina. Mediante esta ilustración se reflejaba una realidad que no había sido demostrada. Por otro lado, es destacable que en el ejemplar del día anterior se hablaba de 253 desaparecidos, y en esta nueva versión se señalaban a 258 muertos. Es decir, no solo se aumentó la cifra, sino que se los confirmó como muertos, generando un mayor impacto.

Como si todo esto fuera poco, el Journal ofrecía una recompensa de $\$ 50.000$ para aquel que identificase al autor de los hechos. Esta recompensa, anunciada hasta en siete ocasiones en la portada, ponía de manifiesto el poder económico del diario; teniendo en cuenta que esa suma de dinero equivaldría a cerca de $\$ 1.300 .000$ actuales. Sin embargo, este dinero nunca fue reclamado ya que nunca se encontró siquiera un sospechoso. Esta recompensa también era un claro ejemplo de porque Hearst llamaba a su método periodístico periodismo activo. El diario no solo reporta los sucesos, sino que participa de ellos; el año anterior fue rescatando a Evangelina Cisneros $^{5}$, y ahora ofreciendo una recompensa incitando a sus lectores a involucrarse también.

Luego del incidente del Maine, el gobierno estadounidense negociaba con España tratando de evitar la escalada del conflicto. Sin embargo, el gobierno español se negaba a hacer cualquier clase de compensación o desagravio, remarcando su completa inocencia y desconocimiento previo respecto de lo sucedido. Y mientras el gobierno hacía todo lo posible por conseguir la paz, el New York Journal hacía todo lo posible por que se declarara la guerra. El 20 de febrero, apenas cinco días después de la explosión del Maine, el Journal publicaba como titular "Guerra seguro" (War sure). Todavía no existía una declaración de guerra ni nada que indicara que la fuese a haber. Pero el Journal, de todas formas, se adelantaba a los hechos. Más abajo leemos "Todo el país se estremece con fiebre de guerra" (New York Journal, 20 de febrero de 1898). Esta afirmación estaba hecha sin ningún fundamento ya que no había ninguna encuesta que la

\footnotetext{
${ }^{5}$ Sobrina del presidente de Cuba, que iba a ser condenada a muerte por el supuesto asesinato de un soldado español, hasta que un corresponsal de Hearst la rescató y llevó a Estados Unidos.
} 
respaldara. Hearst solo publicó esas frases con la esperanza de que, al difundirse, se convirtieran en verdad.

E1 22 de marzo se dio a conocer el reporte de la comisión estadounidense respecto del hundimiento del Maine, que concluía que la explosión había sido externa. Si bien el reporte no decía nada sobre el culpable, el Journal afirmaba sin miedo a equivocarse que todo había sido planeado por el gobierno español. Se leía en la portada del diario "Nada justifica posponer la intervención en Cuba" (New York Journal, 22 de marzo de 1898).

Las tensiones entre los gobiernos no dejaron de crecer. Todas las negociaciones fracasaron y el 25 de abril el Congreso de los Estados Unidos le declaró la guerra a España. Así comenzó formalmente la intervención de Estados Unidos en Cuba. El Journal imprimió una edición especial para anunciar esta noticia. En la portada podemos leer "EL CONGRESO DECLARA LA GUERRA” en mayúsculas muy grandes. En el encabezado, el diario presume su circulación, la cual ya había superado el millón, "Más de un millón doscientos mil cada día" (New York Journal, 25 de abril de 1898). 


\section{Imagen 3. New York Journal, 25 de abril de 1898}

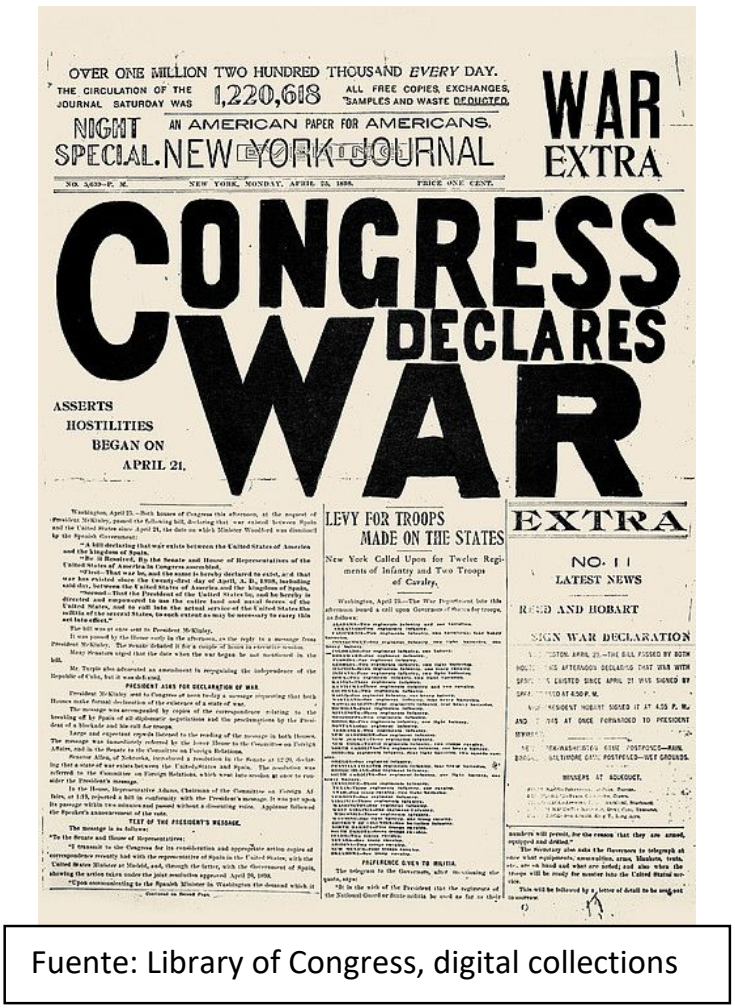

Miles de voluntarios se enlistaron en los días siguientes al grito de "Remember the Maine, to hell with Spain" (Recuerden el Maine, al infierno con España), el cual se volvió un grito de guerra muy popular durante el conflicto. En cuestión de días las primeras tropas comenzaron a zarpar (Bosch, 2010: 294-295). Y entonces el Journal festejó lo que consideraba su éxito con un titular que pasaría a la historia: How do you like the Journal's war? (¿Qué les parece la guerra del Journal?) (New York Journal, 3 de mayo de 1898).

El New York Journal apeló a la seguridad como argumento para intervenir en Cuba. Es decir, definió el interés nacional en términos militares. Según Fareed Zakaria, "los hombres de Estado invocan la seguridad para justificar todo comportamiento de política exterior, incluso descaradas rapiñas imperiales". Si bien Hearst era un empresario/periodista 
y no un hombre de Estado, el argumento es el mismo. Estados Unidos no enfrentaba ningún peligro inminente, pero él utilizó la historia del Maine para hacerlo parecer así. "Los hombres de Estado [en este caso periodista o empresario] - que siempre tienen intereses creados [aumentar las ventas del periódico] - saben cómo hacer para que la expansión parezca una acción obligada por la supervivencia de la nación" (Zakaria 2000, 56).

IV.2. El Times: el fin de las alternativas

Una de las primeras cuestiones que notamos al analizar las portadas del Times es la total ausencia de fotos e ilustraciones. Desde luego, hay uso de mayúsculas y de minúsculas, pero no tan desmedido como se vio en el Journal. Vemos entonces como las portadas del Times no estaban diseñadas para causar sensación e impacto en el lector al momento de verlas. 
Imagen 4. New York Times, 16 de febrero de 1898

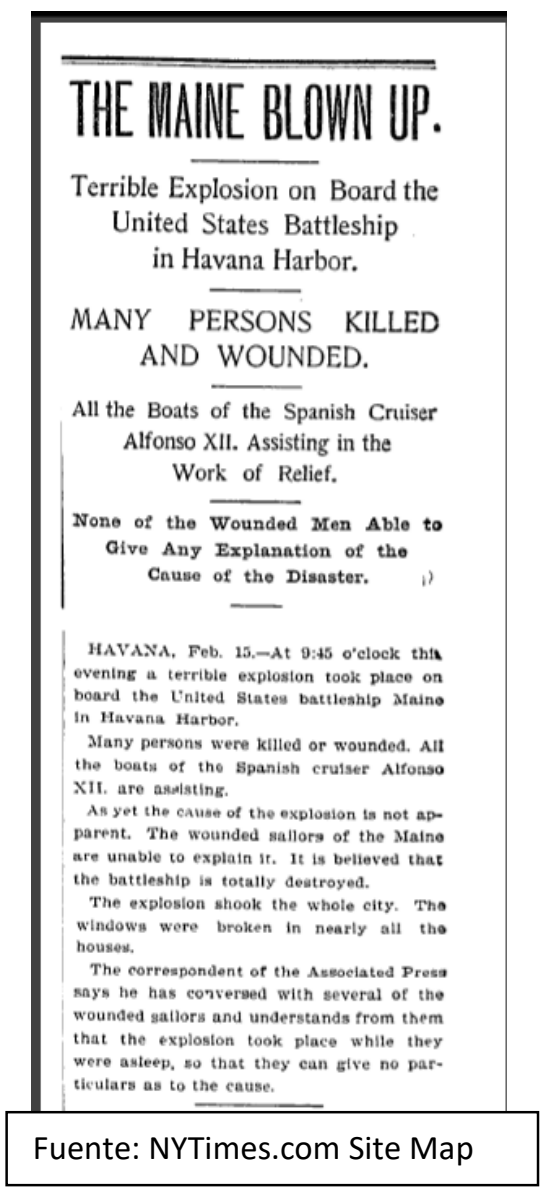

A diferencia del diario de Hearst, el Times no hizo acusaciones, sino que se limitó a dar la información de lo ocurrido. En vez de culpar a España, destacó que el Alfonso XII, un barco español que también se encontraba fondeando en las costas de la Habana, ayudó a los sobrevivientes del Maine; y aclaró que aún no se sabía cuál había sido la causa del accidente. Más adelante, el Times brindó información acerca del Maine, su tripulación y las razones por las cuales se encontraba en Cuba. Siempre con el objetivo de informar a sus lectores y con datos corroborables (New York Times, 16 de febrero de 1898). 
Al día siguiente, mientras el Journal hacía sus conjeturas, el Times aclaró en letras mayúsculas "ONLY THEORY AS TO THE CAUSE OF DISASTER" (SÓLO TEORÍA EN CUANTO A LAS CAUSAS DEL DESASTRE). Y justo debajo declaró que, hasta el momento, todo indicaba que fue un accidente. A lo largo de toda la nota se dio información acerca de los daños causados por la explosión, de los muertos, de los heridos, de los testigos y constantemente repitió que aún no se sabía cuál había sido la causa del incidente. El Times no hizo ninguna mención a una mina submarina puesta por el "enemigo" ni a una "traición española" porque simplemente no había nada que indicase eso (New York Times, 17 de febrero de 1898).

Imagen 5. New York Times, 17 de febrero de 1898

\section{THE MANE DISASTER \\ Capt. Sigsbee Reports the Num- ber of Dead as 253 and of \\ Survivors as 96 . \\ ONLY THEORY AS TO THE CAUSE OF DISASTER. \\ All the Information at Hand Tends to Indicate That the Loss Was Due to an Accident, \\ Xost of the Heactued Mex Bent to Key West ea the Wrad Ilno Etenm- ex Olivette.}

Nothing has teen tearned at the ceuse of the lose of be battle ahip stains. She is a bursed awd broken wreck, reating on the bottom of Jinvann Harboe, nod two officera and $2 \mathrm{kl}$ mallora have perished. There is mo evidence to prove or aispeove treochetr. Nawat wen tell of many trays in ohbeh tho disaster eovid pave base caused by mectdent which eovild mot have been sukrded seainat.

Fuente: NYTimes.com Site Map 
Dos semanas después del incidente del Maine, el Times se proclamó a favor de la intervención, pero de una forma muy distinta a la del Journal. El Times estaba a favor de la independencia cubana, pero hasta este momento no creía que Estados Unidos debiera involucrarse militarmente en el conflicto (New York Times, 2 de marzo de 1898). Según Gleijeses (2003) el New York Times cambió su opinión debido a la política interna, es decir, debido a su apoyo a la administración y a la presión popular. Luego de la explosión del Maine la opinión pública a favor de la intervención había crecido considerablemente. Incluso mucha gente importante dentro del gobierno se manifestaba a favor ${ }^{6}$. Ante esto, Ochs prefirió cambiar su postura hacia la intervención en lugar de desafiar abiertamente al gobierno y a sus lectores. Sin embargo, como se puede ver, no se apoyaba en la destrucción del Maine para justificar la intervención (ya que no podía probar la culpabilidad de España), de hecho, el Times fue muy crítico del Maine como grito de guerra a lo largo de todo el conflicto. En lugar de esto, Ochs se centró en el desgobierno de la isla y como esto repercutía en los intereses de la Nación. Pero el Times no definió los intereses de la Nación en términos de seguridad como el Journal. El Times no enarboló la bandera del Maine sino la del orden, los negocios y la prosperidad económica. Esos son los intereses que quiso defender.

${ }^{6}$ Uno de ellos, como ya se dijo, era el entonces secretario adjunto para la Armada, Theodore Roosevelt. 
Imagen 6. New York Times, 2 de marzo de 1898

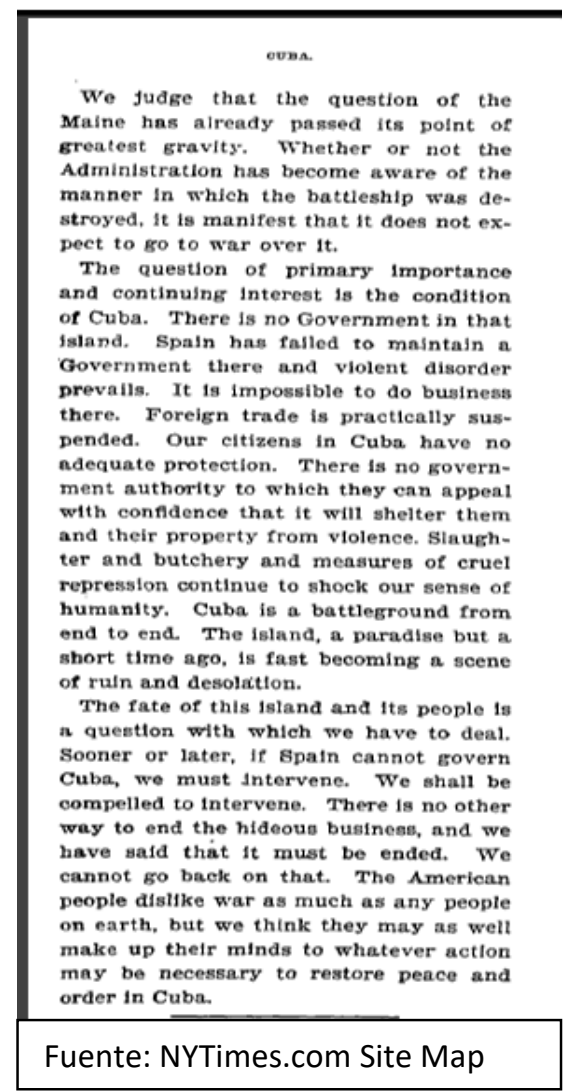

El 2 de abril, unos días después de que los resultados de las investigaciones del Maine se dieron a conocer, el Times advertía que, si bien el tribunal norteamericano había dicho que la explosión fue provocada desde el exterior de la embarcación, eso no significaba necesariamente que se hubiese hecho con el consentimiento del gobierno español. "El gobierno español no autorizaría un acto que aseguraría la expulsión de España de este hemisferio. Ese debió ser el acto irresponsable y desautorizado de un loco o un fanático." Sin embargo, el Times no terminaba por perdonar al gobierno español, ya que a continuación lo acusaba de ser moral y legalmente responsable de lo sucedido. No haber sido capaces de anticipar ese suceso e impedirlo, hacía que la destrucción del Maine fuese un acto de guerra como 
si el mismo gobierno hubiese apretado el botón que detonó la mina. Y agregaba que las alternativas de España eran esa terrible guerra o abandonar para siempre el hemisferio americano en el cual su influencia solo les había traído desgracia (New York Times, 2 de abril de 1898).

De nuevo, el Times se limitaba solo a lo que podía probar para defender esta intervención. No acusaba al gobierno español de haber planeado y ejecutado la explosión del Maine porque no había prueba de ello. De lo único que existía prueba es que el origen de la explosión había sido externo. Entonces el Times se apoyaba en eso para relativizar la importancia del consentimiento del gobierno español. Haya dado o no autorización, no había impedido que la explosión del Maine ocurriera, y eso era suficiente.

\section{El curso de la guerra}

\section{V.1. El Journal: la venganza del Maine}

Para el 22 de abril, el puerto de la Habana, y toda la costa este de la isla, ya había sido bloqueada. Dos meses más tarde, el 26 de junio, las tropas estadounidenses lograron desembarcar en Daiquirí, en la zona oriental de la isla; y tras algunas escaramuzas, tomaron Santiago de Cuba el 3 de julio (Smith, 1994: 119-159). Después de esto, la guerra ya estaba prácticamente decidida. Estados Unidos aprovechó entonces no solo para ir tomando el resto de Cuba y las Filipinas sino también para tomar Puerto Rico. Esta isla tenía un gran valor comercial y militar, y sus habitantes, al igual que los cubanos, deseaban librarse del gobierno español. De esta manera, para cuando los españoles se rindieron, los estadounidenses tenían una posición más que ventajosa para negociar (Bachrach 1991, 86-87).

Con cada victoria estadounidense, por más pequeña que fuera, el New York Journal hacía alusión al Maine en sus titulares, aclamando al ejército estadounidense. Posiblemente, Hearst fue el periodista que más utilizó aquel incidente naval como bandera de guerra, convirtiéndolo en un verdadero símbolo de nacionalismo, heroísmo y patriotismo.

E1 5 de julio el New York Journal festejaba la victoria de la armada de su país en las costas de Santiago y la captura del almirante español Pascual Cervera. En la portada del diario podemos ver el dibujo de un águila calva, 
símbolo nacional, saludando con un sombrero con estrellas en un festejo de la victoria en el día de la independencia estadounidense (el 4 de julio). Este es un claro ejemplo del uso de simbología nacionalista con el objetivo de agradar al público y unir simbólicamente el destino de las dos naciones.

\section{Imagen 7. New York Journal, 5 de julio de 1898.}

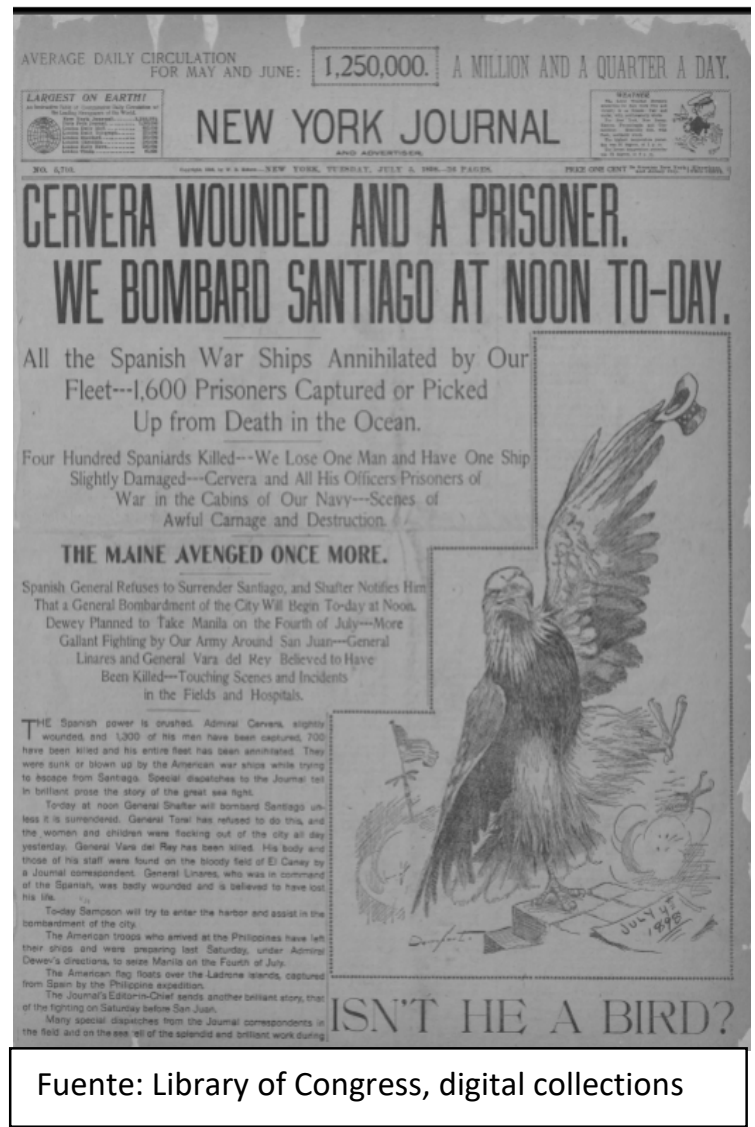

Y, por si esto fuera poco, en el medio de la página, en negrita y mayúscula, se leía "THE MAINE AVENGED ONCE MORE” (EL MAINE FUE VENGADO UNA VEZ MÁS) (New York Journal, 5 de julio de 1898). El hundimiento del Maine era un tema cargado de emoción. El New York Journal, como diario amarillista, es decir, como diario que busca ante todo 
causar sensación, no podía dejar este tema de lado. Lo usaba a su favor siempre que podía, haciendo alusión a él continuamente en sus titulares. Y lejos de conformarse con eso, realizó ferias barriales y otros eventos de este tipo para poder construir un monumento nacional en honor a los caídos en la guerra contra España y especialmente a los "mártires del Maine". Anuncios de estos eventos o de grandes donativos eran frecuentes en las páginas del diario (New York Journal, 26 de julio de 1898).

Estos anuncios eran un claro ejemplo del "periodismo activo" y del ingenio que Hearst había demostrado tener para la autopromoción. Otra muestra de esto se observa en el encabezado de los ejemplares del diario (como el de la imagen anterior). Como había comenzado a hacer unos meses antes, imprimió en el encabezado el número de lectores con que contaba al día de la fecha, 1.250.000; y a esto le agrega una comparación. A la izquierda del nombre del diario los periodistas del Journal elaboraron una tabla con los diarios con mayor circulación en el mundo, donde su diario, por supuesto, figura primero. Del otro lado, a la derecha, el bajo precio del diario, un centavo. $\mathrm{Y}$ al lado del precio del diario, se aclara que cualquier otro cuesta el doble. Esto es algo que aparecería en todos los diarios hasta el final de la guerra.

Este diario también enviaba cartas u objetos tales como banderas a los principales actores de esta guerra; generales, diplomáticos, secretarios, etc. Y cada vez que obtenían una respuesta, mención o agradecimiento por parte de uno de estos no dudaban en publicarlo, mostrándose como un diario interesado en el conflicto, cercano a la gente y con importantes fuentes de información (New York Journal, 22 de julio de 1898).

En otra clara muestra de autopromoción el Journal se jactó de tener tanto acceso a las noticias que acusó al Times de robárselas. "Muchos diarios han tomado ventaja de la superior información del Journal, sin darle el crédito que merece. Diarios como el New York Times no tendrían tanto para publicar si no fuera por diarios como el Journal" (New York Journal, 21 de febrero de 1898). Así como los editores del Times criticaban a los del Journal por su falta de profesionalismo a la hora de publicar las noticias, los del Journal criticaban a los del Times por no tener tantas fuentes de información como ellos.

El 15 de julio el Journal festejó la capitulación de Santiago de Cuba, apelando nuevamente a símbolos patrióticos. Otra vez apareció el águila 
calva. Pero esta vez, con el sombrero con estrellas sobre su cabeza. Esta águila tiene en su extremidad izquierda un cabrito, con el nombre de Santiago mientras otro con el nombre de La Habana huye, simbolizando así la captura de la ciudad de Santiago por parte del ejército estadounidense. La ciudad de Santiago está siendo llevada al nido del águila donde ya se encuentran Manila (ciudad capital de Filipinas), la flota de Cervera y Montojo (Comandante General de todas las estaciones navales españolas de Filipinas). Según el Journal, esta victoria en Cuba demostró que el ejército de Estados Unidos no solo era invencible en el mar sino también en tierra. Ya no estaban solo hundiendo embarcaciones y destruyendo fortalezas, sino que ahora liberaban ciudades. Y no cualquier ciudad, la segunda ciudad más importante de la isla. "Dos flotas, un ejército, una provincia, y la segunda ciudad en Cuba perdidas. ¿Qué más quiere España?” (New York Journal, 15 de julio de 1898).

\section{Imagen 8. New York Journal, 15 de julio de 1898}

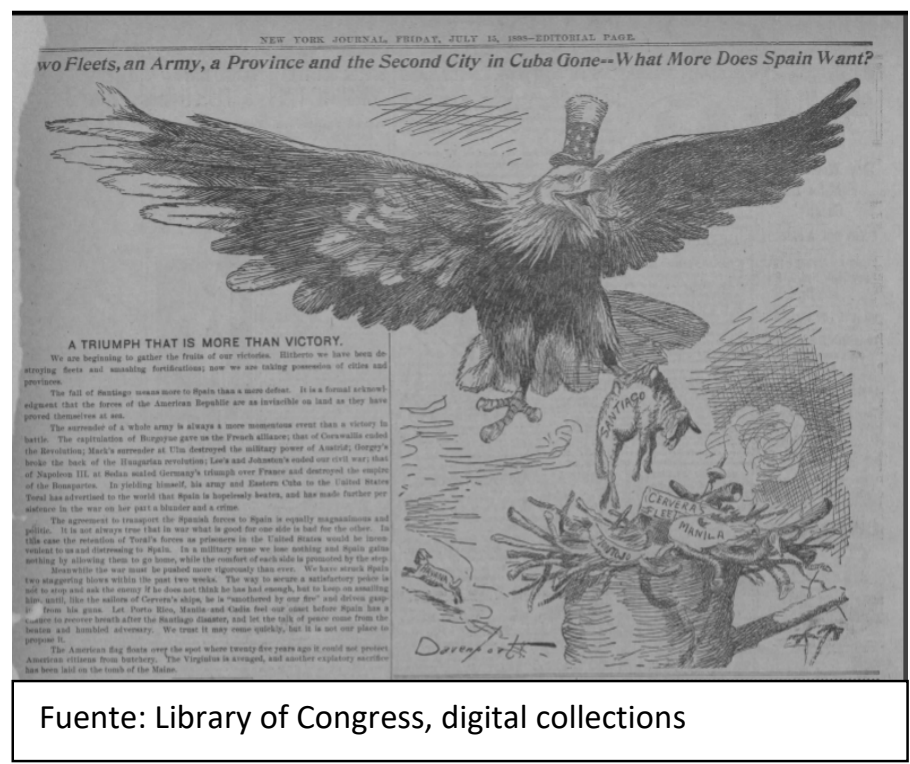

Y hacia el final de la nota encontramos una nueva mención al Maine. " $L a$ bandera americana ondea en el mismo lugar donde hace veinticinco años 
esta no pudo proteger a ciudadanos americanos de ser masacrados." Esta frase refiere a un episodio ocurrido durante la Guerra de los Diez Años, donde un cañonero español detuvo a un barco norteamericano, el Virginius, y lo llevó a Santiago de Cuba. Allí las autoridades españolas de la isla ejecutaron sumariamente al capitán, a treinta y seis miembros de la tripulación y a dieciséis pasajeros. Este acto de guerra causó profunda indignación en la opinión pública estadounidense y no había sido reparado por el gobierno español (Zakaria, 2000: 103-104). Pero ahora "el Virginius ha sido vengado, y otro sacrificio ha sido hecho en honor al Maine" (New York Journal, 15 de julio de 1898). En pocas pero simples y contundentes palabras el Journal comparó el Virginius con el Maine volviéndolos parte de lo mismo, episodios donde los intereses estadounidenses, definidos en términos de seguridad, se vieron vulnerados a manos españolas en Cuba.

Además del episodio del Maine, el New York Journal hacía referencia constantemente a las barbaridades de los españoles. Ya antes de que su país declarara la guerra, el diario mencionaba lo mal que los españoles trataban a sus prisioneros de guerra y a la población civil cubana, comparándolos con bestias. Valeriano Weyler, general a cargo de las tropas españolas, fue un claro ejemplo de esto. Si bien trató de pésima manera a los cubanos impulsando la política de encerrar a la población civil en campos de concentración, la prensa estadounidense también lo acusó de crímenes que nunca cometió, como arrojar cubanos de acantilados para ser devorados por tiburones o fusilar a los enfermos y darles sus cuerpos de comer a los perros. Fue apodado de diversas maneras, entre ellas "el bruto, el devastador de haciendas, el destructor de familias, el azote de las mujeres y el exterminador de hombres" (Bachrach, 1991: 38). Durante la guerra la prensa amarillista continuó con este tipo de difamaciones. Según el Journal, los soldados españoles no respetaban hospitales de guerra, banderas de rendición, ni a la propia Cruz Roja. 


\section{Imagen 9. New York Journal, 15 de julio de 1898.}

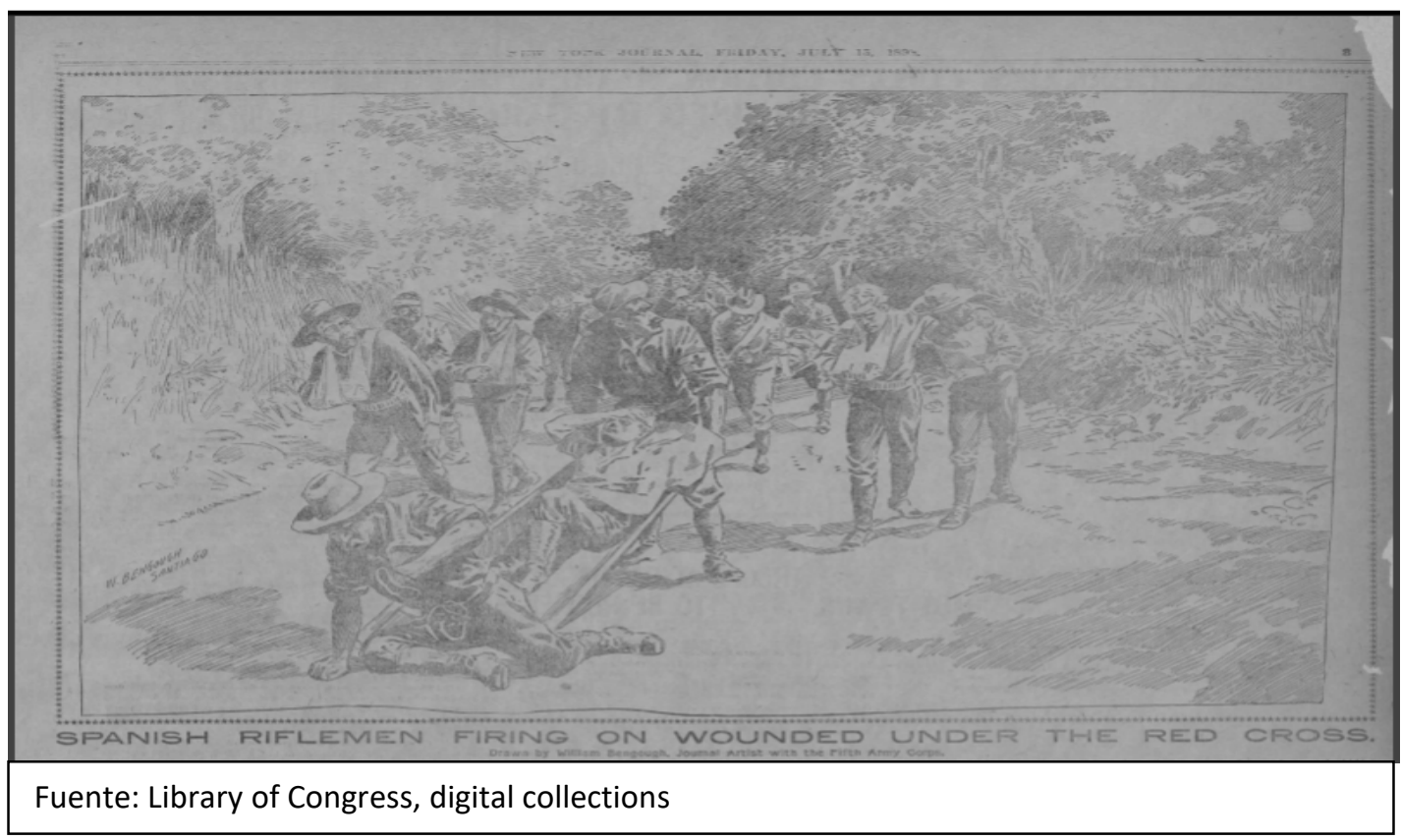

En la ilustración aparecen rebeldes cubanos heridos que aparentemente están siendo atacados. En el texto que sigue abajo mencionaba que eran los españoles quienes los atacan, pero en la ilustración esto no es fácilmente visible. Y aunque se vieran, es un dibujo, no una foto. Es decir, no se encuentran pruebas fehacientes de que lo que el diario decía fuera efectivamente cierto. La imagen solo reconstruía algunos episodios ficticios (New York Journal, 15 de julio de 1898). Es muy común que durante una guerra se buscase deshumanizar al enemigo. De esta manera nadie dudaba que la guerra fuera justa, de que lo que el país estaba haciendo era lo correcto y de que el enemigo merecía el castigo.

Hearst reconoció la lucha y la capacidad de autogobernarse de los cubanos antes que cualquier otro estadounidense ya que, desafiando al gobierno norteamericano, reconoció por su cuenta la independencia cubana en su diario en abril de 1896. El Journal anunció que los ciudadanos 
cubanos eran independientes y animados por el mismo espíritu que los patriotas de Filadelfia en 1776 (Bachrach 1994, 37). El 16 de julio, el Journal expresaba claramente que Cuba debía quedar para los cubanos. "Cuba for the Cubans" (New York Journal, 16 de julio de 1898).

\section{Imagen 10. New York Journal, 16 de julio de 1898}

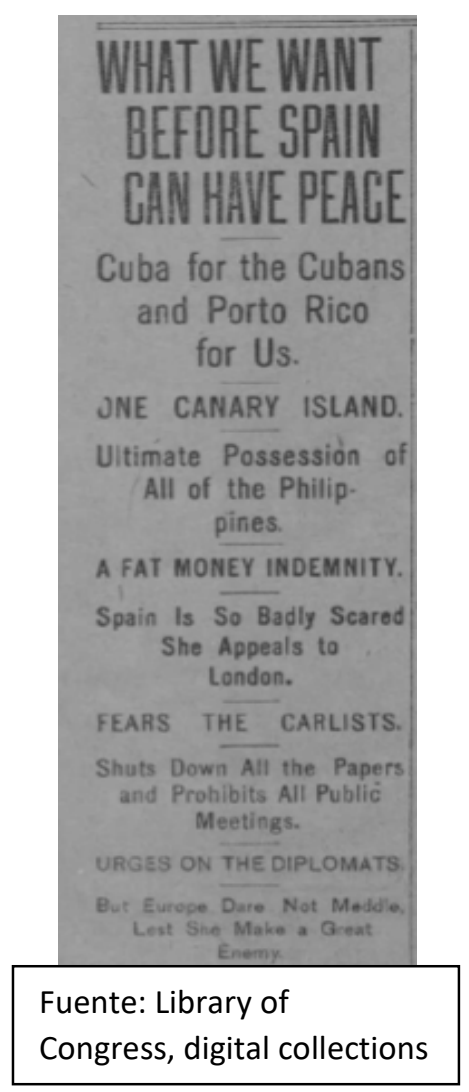

Un aspecto de William Hearst que muchos podrían considerar extraño y hasta contradictorio es que él era aislacionista, creía que el contacto de Estados Unidos con el resto del mundo debía limitarse a un mínimo indispensable, y sin embargo dio su total apoyo a esta intervención en suelo extranjero. Una explicacón para esto podría ser que Hearst consideraba que ese mínimo indispensable era todo aquello que fuera para proteger los 
intereses de la nación, y para 1898 estos intereses eran muy vulnerables. Entre 1889 y 1908, dice Zakaria (2000, 188), se afirmó la decisión de expandir los intereses norteamericanos por todo el mundo, y una vez hecho esto, las amenazas a los intereses del país comenzaron a proliferar. Surgieron nuevas amenazas, pero solo porque los intereses de Estados Unidos se habían expandido.

El interés nacional parecería ser entonces terminar con la barbarie española y liberar al pueblo cubano. Ponerle fin a las injusticias y los crímenes que los soldados españoles cometían contra los cubanos, como la violación de la bandera de la Cruz Roja (New York Journal, 12 de julio de 1898) para que la isla de Cuba pudiera conseguir su tan ansiada independencia (New York Journal, 16 y 24 de julio de 1898). Parece un interés demasiado solidario pero, para Hearst, esto era exactamente lo que hacía a Estados Unidos tan especial y diferente. Este país estaba dispuesto a involucrarse militarmente en una guerra para salvar y mejorar el mundo expandiendo la libertad y la prosperidad económica, sacrificando las vidas de sus jóvenes. Aunque de esta forma también aseguraban su propia seguridad evitando que incidentes como el del Virginius o el del Maine se repitieran en el futuro. El New York Journal define así los intereses de su Nación en términos humanitarios y de seguridad.

\section{V.2. El Times: la obligación de liberar Cuba}

Según Ochs la obligación de Estados Unidos consistía en remover a España del hemisferio occidental para extender la civilización y el desarrollo económico para que la mayor cantidad de gente posible pudiera alcanzar la felicidad y poner sus dones al servicio de la humanidad. Permitirle a España continuar con sus inhumanas políticas sería un error, los estadounidenses tenían la obligación de liberar Cuba y cuantos territorios pudieran para que estas pudieran desarrollar su verdadero potencial económico (New York Times, 10 de julio de 1898).

Ochs, al igual que Hearst, denunció el maltrato español en las páginas de su diario, pero de una manera más profesional y minuciosa. El 15 de mayo, el Times publicó un detallado informe acerca de la crueldad española desde Cortés y Pizarro hasta ese momento con los campos de concentración en Cuba, la tortura y fusilamientos de prisioneros. La conclusión era que los 
españoles habían sido así siempre y lo seguirían siendo; y que por lo tanto debían ser expulsados de ese hemisferio (New York Times, 15 de mayo de 1898).

Cuba era, según el Times, uno de los lugares más ricos de la Tierra. Pero el mal gobierno español impedía su desarrollo. Las ganancias que la isla estaba generando eran solo una pequeña parte de su verdadero potencial. Cuba sería perfectamente capaz de producir riqueza para sus habitantes y aun así tener un superávit para enviar a España si estuviese bien administrada. (New York Times, 19 de mayo de 1898). Pero el robo y la negligencia de los españoles impedía eso. Y con la guerra, la mala situación económica de Cuba se había hecho más que evidente. Ya no tenía ferrocarril, caminos, agua corriente ni muelles (New York Times, 5 de junio de 1898). De nuevo el diario definía los intereses de la nación como económicos. La paz era buscada pero no como un fin en sí misma sino como un requerimiento para los negocios. "Salvaremos vidas y riquezas [...] desalojando al enemigo de su fuerte posición en la Habana" (New York Times, 12 de mayo de 1898).

Imagen 11. New York Times, 12 de mayo de 1898.

\begin{tabular}{|l|}
\multicolumn{1}{|c|}{ Acrive work ro cusa. } \\
An active and vigorous prosecution of \\
the war is now the most humane policy. \\
We shall save lives and treasure by be- \\
ginning at the earliest moment at which \\
we can prepare ourselves for it the work \\
of dislodging the enemy from his strong- \\
hold in Havana. It is all he has left, ex- \\
cept Puerto Rico, which will be an in- \\
cidental spoil of war, and his home pos- \\
sessions where it is unlikely that we \\
shall attack him unless for the purpose \\
or compelling him to make peace. The \\
fall of Havana would immensely increase \\
the troubles of Spain with her own sub- \\
jects. By taking from her the very thing \\
she is fighting to retain, moreover, we \\
should bring home to her with startling \\
distinctness the question whether it was \\
not time to cry "enough." \\
\hline Fuente: NYTimes.com Site Map \\
\hline
\end{tabular}


A diferencia del Journal, el Times describió a los soldados cubanos de una forma negativa. Al parecer, estos hombres estaban más interesados en saquear y matar españoles que en liberar la isla. Así comenzó la idea de que los cubanos no estaban capacitados para autogobernarse y que, luego de la guerra, habría que establecer un gobierno militar estadounidense para asegurar una transición pacífica (New York Times, 30 de mayo de 1898).

Los oficiales del ejército estadounidense no dejaron que los soldados cubanos tomaran parte activa en los enfrentamientos y en lugar de ello les asignaron roles defensivos y actividades de rutina como exploración, mensajería, cavado de trincheras, etc. Los cubanos se sintieron gravemente ofendidos y a menudo protestaban diciendo que eran soldados, no obreros. Pero sus protestas fueron ignoradas (Smith 1994, 128-129).

El New York Times incluso llegó a admitir que la "Cuba libre" era una quimera. Que los ciudadanos cubanos por los que Estados Unidos había sacrificado tanto no existían. No había en la isla un verdadero sentimiento de República. Más allá de los pocos hombres que formaban el gobierno provisional, no existía una clase política. Tampoco existían ciudadanos formados capaces de cumplir con sus deberes y obligaciones. Los cubanos serían incapaces de establecer una república; al menos por su propia cuenta (New York Times, 7 de agosto de 1898). 
Imagen 12. New York Times, 7 de agosto de 1898.

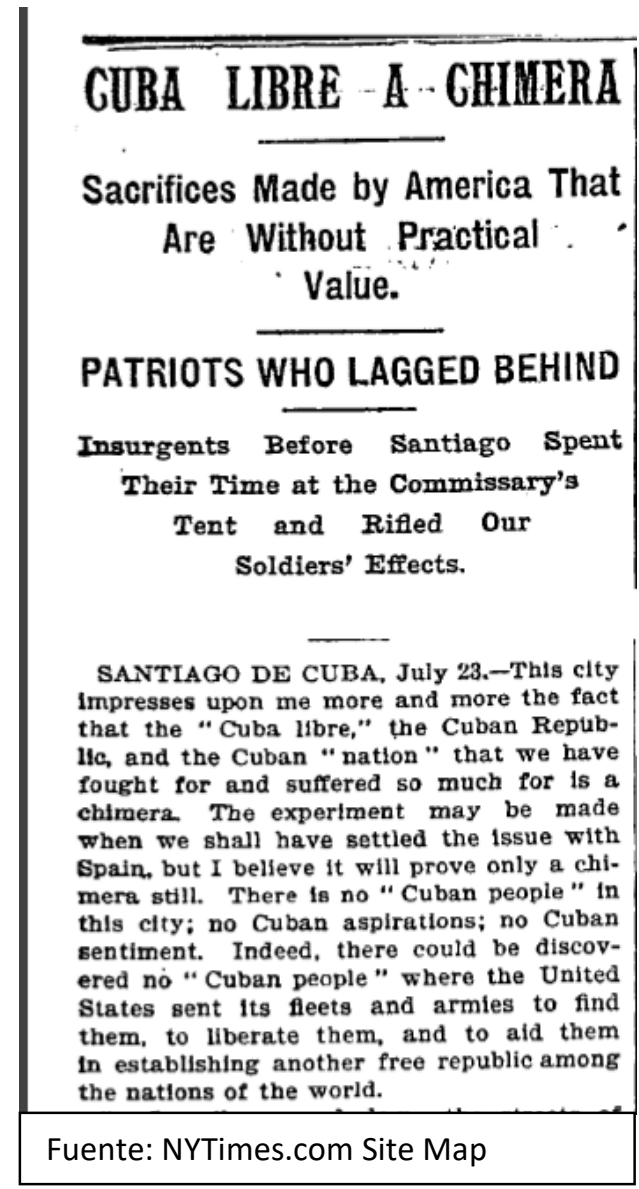

Es importante tener en cuenta que, aunque el Times no manipulaba la información como el New York Journal esto no necesariamente implica que fuera neutral o imparcial ante los hechos, por más que Ochs dijera que sí lo era. Como vimos recién, el Times tomó postura por ciertos temas de la guerra, ya sea por decisión personal o empresarial, consciente o inconscientemente. Adoph Ochs era, al fin y al cabo, un ser humano con sus propias ideas y opiniones. No hay diario que no tenga una línea editorial marcada y el New York Times no fue la excepción (Sylvia Saítta, 1999). 
El diario de Ochs definió los intereses nacionales en términos humanitarios, pero con un análisis más minucioso. El diario detalló todos aquellos maltratos de los que se tenía registro y los remontó al inicio de la conquista española de América. Además, el Times no se preocupó tanto por la seguridad del país, dejando la cuestión del Maine de lado. En cambio, justificó la intervención apelando al interés económico, a lo prospera que podía ser Cuba para los negocios estadounidenses si las tropas españolas se retiraran. Sin embargo, no creía que los cubanos fuesen capaces de mantener un gobierno estable donde florezca el comercio y el progreso, y que por lo tanto los Estados Unidos debían intervenir este gobierno, por lo menos durante sus primeros años, para asegurar un gobierno con bases sólidas.

\section{Conclusiones}

Raúl Sohr afirmó lucidamente que la historia moderna ha demostrado que cuando un Estado choca contra otro mediante el uso de las armas, exige que su prensa se subordine por completo a los intereses nacionales, definidos por el gobierno de turno. Muchas veces, los gobernantes imponen sus aventuras militaristas a toda la nación. La definición de "guerra justa" o "guerra injusta" ha variado históricamente en diversos conflictos de distinto tipo. Sin embargo, los medios gráficos no solo reciben la influencia del gobierno, sino también de los propietarios o los sectores con los que se identifican. La realidad es que los periodistas han demostrado no ser "cruzados" comprometidos en la búsqueda de una verdad oculta en las enrevesadas telarañas del poder. La prensa, que dista de ser neutral, ha sido un medio que fue utilizado por distintos regímenes y por quienes entendieron cómo hacerlo (Sohr 1998, 19-35).

Más o menos distanciados del gobierno de William McKinley, William Hearst y Adolph Ochs, fueron influenciados por este. Persiguiendo cada uno sus objetivos, y utilizando cada uno su método periodístico, defendieron la guerra hispano-americana aludiendo a distintos aspectos los cuales, según ellos, formaban parte del interés nacional.

El objetivo del New York Journal era sencillo, ganar lectores a través del amarillismo para convertirse en el diario más exitoso de la ciudad de Nueva York. Para esto el diario realizaba un enorme trabajo de autopromoción a 
través de distintos elementos como resaltar el número de lectores y el precio del diario en el encabezado de cada ejemplar, carteándose con protagonistas de esta guerra y publicando sus respuestas y organizando eventos en la ciudad. El uso de dibujos y símbolos nacionalistas como el águila calva fueron clave para llamar la atención y agradar al público.

La postura de este diario fue clara desde antes de la explosión del Maine. Hearst demandaba la intervención militar de Estados Unidos en la isla de Cuba para terminar con el cruel mandato español y concederles a los cubanos la independencia. Para esto apeló a distintos argumentos. Uno de ellos, probablemente el más destacado, fue la amenaza de la seguridad nacional, primero resaltando la noticia de la explosión del Maine y luego haciendo alusión al hecho en cada oportunidad que se presentara. El hecho de que tan solo 266 marineros murieran en un poco claro accidente frente a las costas de la Habana no parecía representar un peligro inminente para el país entero, pero haciendo acusaciones sin evidencias, declaraciones sin respaldo y esparciendo rumores sin fuentes declaradas, el Journal convirtió este accidente en una bandera de guerra para todo el país, un símbolo de que la nación estaba en peligro.

El New York Journal también definió el interés nacional en términos humanitarios al denunciar - y exagerar - los maltratos del ejército español contra la población cubana. Hearst describió a los españoles siempre con connotaciones negativas y a los cubanos siempre de forma positiva, casi llegando a definir la guerra como una lucha entre el bien y el mal. Los españoles robaban, torturaban, violaban y mataban. Encerraban a la población civil en campos de concentración donde morían de hambre y enfermedades. Los cubanos en cambio, era descriptos en las páginas del Journal como "héroes" que luchaban por la libertad de su patria, igual que los Padres Fundadores lo habían hecho a finales del siglo XVIII.

El New York Times hizo las cosas de manera muy distinta. Su método periodístico tradicional no se basaba en el sensacionalismo. No utilizaba fotografías ni dibujos, ya que las fotografías todavía no eran lo suficientemente nítidas y lo que se dibujaba podía no ser cierto. El Times no exageraba las noticias, no publicaba rumores, ni hacía acusaciones sin datos que las respaldaran. Su objetivo era destronar a la prensa amarillista como la más exitosa, pero sin convertirse en amarillista. 
La posición del Times respecto del conflicto en Cuba y los intereses de Estados Unidos respecto de este no fue tan constante como la del Journal, sino que fue evolucionando paulatinamente. A mediados del siglo XIX el Times no estaba para nada interesado en la isla de Cuba. Cuando comenzaron los conflictos con España este apoyó la independencia de la isla, pero sin la intervención de Estados Unidos. Solo la explosión del Maine lograría poner al diario a favor de la intervención, aunque no de inmediato. Tendrían que pasar algunas semanas, durante las cuales el apoyo popular por la guerra creció marcadamente, para que el Times aceptara que las opciones se habían agotado.

El New York Times no utilizó el hundimiento del Maine como argumento para justificar la guerra. Como no podía probar a ciencia cierta que el hundimiento hubiese sido culpa de España, prefirió hacer el asunto a un costado y centrarse en otros aspectos. Al igual que el Journal, el Times definió los intereses de la nación en términos humanitarios, denunciando las crueldades de los españoles, pero con ciertas diferencias. Este diario tradicional, en vez de exagerar los acontecimientos presentes, hizo un análisis histórico para señalar lo poco que la administración española había evolucionado. Los maltratos por parte de los soldados españoles hacia las poblaciones americanas habían ocurrido siempre y probablemente seguirían ocurriendo si se los dejaba.

Además, el Times no defendió la independencia cubana. Sus noticias señalaban al común de los cubanos como salvajes sin ninguna experiencia en las tradiciones republicanas. Es así como el New York Times dio el último giro en este aspecto, apoyando la idea de ocupar la isla por tiempo indefinido hasta asegurarse que la situación no volvería a sumirse en el caos.

Todo esto estaba acompañado en las páginas del Times del aspecto económico. La administración española era mala no tanto por los actos de violencia sino por la mala administración de los recursos de la isla y por los estragos que la guerra provocaba en las actividades económicas. Cuba era un gran mercado para Estados Unidos el cual nunca podría ser adecuadamente explotado mientras este siguiera en manos españolas. Y la administración cubana no era confiable porque los cubanos castigarían a los españoles civiles o a los cubanos que hayan sido aliados del régimen español, los cuales eran todos hombres de negocios. 
A pesar de que uno era el diario más amarillista de su época y el otro el más tradicional, la retórica de ambos estuvo influenciada por la política expansionista de su gobierno. Hubo diferencias, como ya vimos, pero ambos dieron su apoyo a esta guerra y su carácter expansionista. Ambos diarios, más o menos a su pesar, consideraron intervenir en la guerra hispanoamericano como algo indispensable para la defensa de los intereses nacionales.

Al final de la guerra el New York Journal había perdido grandes sumas de dinero en cubrir la guerra, dinero que sus ventas no habían recuperado completamente. Hearst pudo saborear la aventura que él había premeditado, pero económicamente no le produjo más que pérdidas (Bermesolo 1962, 232). El diario había multiplicado por treinta su cantidad inicial de lectores, pero el derroche de Hearst en salarios, sobornos, corresponsales, barcos, impresoras, cámaras fotográficas y dibujantes, hizo que sus pérdidas fueran aún mayores que sus ganancias. El New York Times en cambio había demostrado lo rentable que el periodismo tradicional y conservador podía ser. Adolph Ochs solo había triplicado su tirada inicial, pero a diferencia de su rival fue mucho más precavido con los gastos de la cobertura. El New York Times no envió corresponsales a la isla de Cuba, sino que obtuvo las noticias de manera gratuita a través de los telegramas de la Associated Press. No se molestó en usar fotografías, cuya calidad no llegaba a reflejar la realidad, ni en contratar dibujantes. Fue austero en sus gastos, pero minucioso en su redacción y explicación de los hechos. Esto le valió un prestigio que continuaría más allá de la guerra y que finalmente lo convertiría en un gran diario, mientras que el Journal caería en el olvido.

El amarillismo no produjo las ganancias esperadas ni se ganó el respeto del público educado o del mundo periodístico profesional. Los lectores de los diarios tradicionales continuarían siendo quienes construyeran, según ciertas visiones, la opinión pública de las ciudades, de los estados y de la Nación entera (Pomerantz 1958).

\section{Referencias}

Bachrach, Deborah. 1991. The Spanish-American War. Farmington Hills: Greenhaven Press Incorporated. 
Bermeosolo, Francisco. 1962. "La opinión pública norteamericana y la guerra de los Estados Unidos contra España”. Revista de estudios politicos 123: 219-234.

Bosch, Aurora. 2010. Historia de Estados Unidos 1776-1945. Crítica: Barcelona.

Campbell, W. Joseph. 2001. Yellow journalism: Puncturing the myths, defining the legacies. Westport: Greenwood Publishing Group.

- 2013. The year that defined American journalism: 1897 and the clash of paradigms. Londres: Routledge.

Cortada, James. 1974. "The New York Times, Spain and Cuba, 1851-1869”. Revista de Historia de América 77/78: 61-75.

Davis, Elmer. 1921. History of the New York Times 1851-1921. New York: The New York Times.

Glazier, Philip. 2004. Yellow Journalism and the USS Maine Explosion: An Analysis of Yellow Journalism's Dominant Coverage of the USS Maine Explosion, and How It's Coverage Affected the Traditional Press. Asheville: University of North Carolina.

Gleijeses, Piero. 2003. "1898: The Opposition to the Spanish-American War”. Journal of Latin American Studies 35 (4): 681-719.

Monclús, Julián Companys. 1998. La prensa amarilla norteamericana en 1898. Madison: Sílex.

Offner, John L. 1992. An unwanted war: The diplomacy of the United States and Spain over Cuba, 1895-1898. Chaper Hill: UNC Press Books.

Pomerantz, Sidney. 1958. "The Press of a Greater New York, 18981900". New York History 39 (1): 50-66.

Saad, Anuar. 2011. "El sensacionalismo o la 'insurrección' de las masas”. Razón y palabra 78.

Saítta, Sylvia. 1999. Regueros de tinta: el diario 'Crítica' en la década del 20. Buenos Aires: Sudamericana.

Smith, Joseph. 1994. The Spanish-American War, Conflict in the Caribbean and the Pacific, 1895-1902. New York: Longman Publishing.

Smythe, Ted C. 2003. The Gilded Age Press, 1865-1900. Westport: Praeger Publishers.

Sohr, Raúl. 1998. Historia y poder de la prensa. Barcelona: Andrés Bello. Wilkerson, Marcus. 1967. Public Opinion and the Spanish-American War: A study in War Propaganda. L. A.: Baton Rouge. 
Whyte, Kenneth. 2009. The uncrowned king: The sensational rise of William Randolph Hearst. Nueva York: Vintage.

Zakaria, Fareed. 2000. De la riqueza al poder: los orígenes del liderazgo mundial de Estados Unidos. Barcelona: Gedisa Editorial.

\section{Fuentes}

New York Journal, del 16 de febrero de 1898 al 13 de agosto de 1898. Disponibles en: Library of Congress, digital collections.

New York Times, del 16 de febrero de 1898 al 13 de agosto de 1898. Disponibles en: NYTimes.com.

New York Times. 9 de abril de 1935. "Adolph S. Ochs Dead at 77; Publisher of Times Since 1896, obituary”. 